\title{
sciendo
}

\section{The impact of cryptocurrency on the efficient frontier of emerging markets}

\author{
Karlo Ćosić \\ Croatia \\ karlo.cosic7@gmail.com \\ Anita Čeh Časni \\ Faculty of Economics and Business, University of Zagreb, Croatia \\ aceh@efzg.hr
}

\begin{abstract}
Cryptocurrencies are a sweltering topic in modern times of investment strategies. Since the cryptocurrency market is classified as an emerging market, in this paper a portfolio of emerging markets is compiled from the indices of four European Union (EU) countries and one cryptocurrency. The aim of this paper is to investigate how the incorporation of the Bitcoin cryptocurrency into the portfolio affects the performance of the portfolios of these countries. Moreover, by drawing an efficient frontier, the paper identifies where Bitcoin stands relative to other indices in the portfolio. The countries whose indices were used in the analysis are: Croatia, Hungary, Romania and Poland during the period from July 13, 2018 to June 07, 2019. The method used for an efficient frontier formation is Markowitz's Modern Portfolio Theory (MPT). By applying this theory, the minimum variance portfolio at the efficient frontier was created for the portfolio with and without the cryptocurrency. The empirical analysis indicates that Bitcoin improves the effectiveness of the portfolio in emerging markets of the selected EU countries, where the expected risks of a portfolio that includes the cryptocurrency are smaller and with higher returns than those of portfolios without Bitcoin. From the Markowitz's theory point of view, the results of the empirical analysis also indicate that Bitcoin is on the efficient frontier. Since all instruments on the efficient frontier according to the modern portfolio theory are efficient, it can be concluded that investments in such instruments depend on investor's risk aversion.
\end{abstract}

Keywords: Bitcoin, cryptocurrency market, efficient frontier, emerging markets, Markowitz modern theory.

JEL classification: C02, C60, D53, E22.

DOI: $10.2478 /$ crebss-2019-0012

Received: October 31, 2019

Accepted: November 29, 2019

\section{Introduction}

This paper studies the impact of cryptocurrency on the investment portfolio by applying the Markowitz method, as given in Markowitz (1959). The analysed portfolio consists of four stock indices and one cryptocurrency. Stock indices selected for this 
research are representative indices of European Union emerging countries, namely, Croatia, Hungary, Romania and Poland. These markets are characterized by the transition to an open market economy with a growing working age population.

The cryptocurrency market can be considered as an emerging market that is growing year by year and its potential exceeds all expectations.

Houben and Snyers (2018) pointed out that cryptocurrency is a digital representation of value that is alternative to government-issued legal tender and it is independent of any central bank.

Andrianto and Diputra (2018) stated that Bitcoin became the most widely used digital currency with the largest market capitalization among other digital currencies. This study is limited only to Bitcoin because of its largest trading volume.

The main goal of this paper and the reason for including cryptocurrency in the portfolio is to see how Bitcoin affects the portfolio and the formation of an efficient emerging market frontier. Accordingly, it is desirable to see how the inclusion of cryptocurrency in the portfolio will affect standard deviation and expected returns. Given that cryptocurrency prices are characterized by high volatility and are influenced by supply and demand, it is logical to assume that returns will be significantly higher relative to other portfolio components, but there will also be greater risk for investors.

This paper is organized as follows, after brief introduction, in section two the literature review is given. In section three, data and methodology are provided. Section four presents the results of the empirical analysis. Finally, section five concludes the paper.

\section{Literature Review}

According to Markowitz modern portfolio theory (MPT), Markowitz (1959), it is possible to create a portfolio that, at a certain level of risk, provides the highest rate of return, i.e. a portfolio that has a minimal risk for a given rate of return (Peris, 2018). Mangram (2013) pointed out that the risk component can be measured by using a variety of mathematical formulas and reduced through a diversification concept that targets a properly weighted set of investment assets that together show lower risk factors for investing in any single asset. Furthermore, by plotting an efficient frontier, the best combinations of securities which provide the highest rate of return for a given rate of risk within an investment portfolio can be observed.

Markowitz theory gives considerable importance to diversification and correlation between portfolio components (Markowitz, 1959). Furthermore, it is important to note that Markowitz was the first to associate covariance among stock returns with portfolio risk which made a significant contribution to the investment area, in comparison to the older diversification approach (Škrinjarić, 2013). Many researchers claim that from investing point of view, correlation of returns is very important.

Burnsike and White (2016) noted that Bitcoin's price should perform differently relative to other assets as it is influenced by distinct market forces. In addition, market behaviour can be quantified by correlation, a standardized indicator of how assets move together. Related to that, they shown correlation of returns: price independence. Furthermore, they found that Bitcoin's price movements have been isolated and different from those of other asset classes and that Bitcoin is the only asset that keeps steadily low correlations with every other asset. Nevertheless, the maximum correlation that Bitcoin displayed with each of the other assets is the minimum correlation that any of the other paired assets showed with each other.

Chan et al. (2017) analysed best fitting distributions and results of different cryptocurrencies including Bitcoin. The analysis has shown that the best fitting 
distribution for Bitcoin is generalized hyperbolic and that log returns of Bitcoin have semi heavy tails.

Trimborn and Härdle (2019) analysed cryptocurrency investing approach by forming portfolios using S\&P 100 component, DAX30 and Portugal stocks with cryptos. Empirical analysis has shown that addition of cryptos can improve risk-return trade-off of portfolio formation, both in in-sample and out-sample case.

Andrianto and Diputra (2018) analysed the effect of cryptocurrency in the portfolio that consists of six stocks. Stocks used in construction of portfolio are The Kraft Heinz Company (KHC), Wells Fargo \& Company (WFC), The Coca-Cola Company (KO), International Business Machines Corporation (IBM), American Express Company (AXP), and Phillips 66 (PSX). They concluded that cryptocurrency improves the effectiveness of the portfolio. They also shown that Bitcoin allocation ranges from below $1 \%$ to above $90 \%$.

\section{Methodology}

The first hypothesis in this paper suggest that cryptocurrency improves effectiveness of the investment portfolio. The next hypothesis is that inclusion of cryptocurrency will change shape of an efficient frontier.

This paper analyses how inclusion of Bitcoin in the portfolio that consists of four emerging market indices affects the portfolio risk-return points and efficient frontier. The study focuses on Bitcoin since nowadays, cryptocurrencies are increasingly used for investment purposes. Specifics of these virtual currencies like low correlation to other assets and resistance to economic shocks are just some of the reasons why investors want to include them in their portfolio.

For the research purposes, historical data were taken from Thomson Reuters and CoinMarketCap. The data period ranges from July 13, 2018 to June 07, 2019. Emerging stock market indices used in the portfolio are: The main share index of the Zagreb Stock Exchange (CROBEX), the Budapest Stock Index (BUX), Bucharest Exchange Trading Index (BETI), Warsaw Stock Exchange Index (WIG), and cryptocurrency Bitcoin (BTC). Bitcoin is chosen since it has the highest market capitalisation among other cryptocurrencies and because some researchers compare Bitcoin to gold. In the empirical part of the analysis the data is analysed using statistical program "R studio" and the financial and graphics packages.

MPT is used to create minimum-variance portfolios located on the efficient frontier. MPT is in fact the investment backbone for selecting and developing investment portfolios based on maximizing expected returns and minimizing risk, Mangram (2013). After uploading the data into "R studio", it was necessary to calculate weekly returns. Some of codes that were also used in optimization purposes include cor (correlation matrix), cov (covariance matrix) and portfoliofrontier (preparing data for plotting an efficient frontier).

Furthermore, optimization was conducted via solver that is known as "solveRquadprog". With the help of solver mean-variance and tangency optimal portfolio could be established. Using the function getWeights it is possible to calculate portfolio weights and after that step it is possible to draw a bar chart of these portfolio weights (using the function barplot or functions from ggplot2 package).

\section{Results}

Empirical analysis starts with calculating weekly returns presented in Table 1. 
Table 1 Weekly portfolio returns (July 13, 2018 to June 07, 2019)

\begin{tabular}{|c|c|c|c|c|c|}
\hline Date & CROBEX & BUX & BETI & WIG & BITCOIN \\
\hline $20-7-2018$ & -0.0090 & -0.0129 & -0.0045 & 0.0119 & 0.1646 \\
\hline 27-7-2018 & 0.0232 & 0.0213 & 0.0179 & 0.0482 & 0.1046 \\
\hline 3-8-2018 & -0.0059 & 0.0225 & 0.0059 & -0.0017 & -0.0937 \\
\hline $10-8-2018$ & 0.0075 & -0.0161 & 0.0081 & -0.0175 & -0.1840 \\
\hline 17-8-2018 & -0.0101 & 0.0073 & 0.0038 & -0.0132 & 0.0621 \\
\hline 24-8-2018 & 0.0013 & -0.0067 & 0.0105 & 0.0419 & 0.0210 \\
\hline $31-8-2018$ & 0.0009 & 0.0284 & 0.0003 & 0.0109 & 0.0462 \\
\hline $7-9-2018$ & -0.0087 & -0.0012 & 0.0036 & -0.0351 & -0.0845 \\
\hline $14-9-2018$ & -0.0070 & -0.0251 & -0.0172 & -0.0112 & 0.0070 \\
\hline 21-9-2018 & 0.0054 & -0.0135 & 0.0266 & 0.0113 & 0.0336 \\
\hline 28-9-2018 & -0.0121 & 0.0381 & 0.0036 & 0.0122 & -0.0136 \\
\hline 5-10-2018 & -0.0087 & -0.0061 & 0.0167 & -0.0092 & -0.0033 \\
\hline $12-10-2018$ & 0.0034 & -0.0163 & -0.0189 & -0.0349 & -0.0540 \\
\hline 19-10-2018 & 0.0011 & 0.0228 & 0.0243 & 0.0047 & 0.0300 \\
\hline 26-10-2018 & 0.0131 & -0.0341 & -0.0221 & -0.0534 & 0.0014 \\
\hline 2-11-2018 & -0.0158 & 0.0333 & 0.0178 & 0.0537 & -0.0134 \\
\hline $9-11-2018$ & 0.0092 & 0.0378 & 0.0109 & 0.0156 & -0.0004 \\
\hline $16-11-2018$ & -0.0168 & 0.0190 & -0.0096 & -0.0304 & -0.1357 \\
\hline 23-11-2018 & -0.0155 & 0.0013 & -0.0061 & 0.0273 & -0.2489 \\
\hline 30-11-2018 & 0.0000 & 0.0184 & 0.0166 & 0.0291 & -0.0789 \\
\hline $7-12-2018$ & -0.0084 & -0.0182 & 0.0022 & -0.0042 & -0.1610 \\
\hline $14-12-2018$ & 0.0111 & 0.0186 & -0.0128 & 0.0095 & -0.0533 \\
\hline 21-12-2018 & -0.0037 & -0.0137 & -0.2083 & -0.0191 & 0.1838 \\
\hline 28-12-2018 & 0.0122 & -0.0112 & 0.0632 & 0.0074 & 0.0070 \\
\hline 4-1-2019 & -0.0109 & 0.0254 & 0.0331 & 0.0036 & -0.0170 \\
\hline $11-1-2019$ & 0.0027 & 0.0183 & -0.0570 & 0.0217 & -0.0452 \\
\hline 18-1-2019 & 0.0142 & 0.0150 & -0.0054 & 0.0182 & -0.0080 \\
\hline 25-1-2019 & 0.0016 & -0.0136 & -0.0207 & 0.0087 & -0.0160 \\
\hline $1-2-2019$ & -0.0012 & 0.0007 & -0.0033 & -0.0022 & -0.0316 \\
\hline 8-2-2019 & -0.0018 & -0.0315 & 0.0722 & -0.0166 & 0.0500 \\
\hline $15-2-2019$ & 0.0071 & 0.0119 & 0.0132 & -0.0068 & -0.0126 \\
\hline $22-2-2019$ & 0.0039 & 0.0157 & 0.0142 & 0.0075 & 0.1010 \\
\hline $1-3-2019$ & 0.0092 & -0.0159 & -0.0134 & -0.0097 & -0.0371 \\
\hline 8-3-2019 & -0.0168 & 0.0029 & 0.0233 & -0.0147 & 0.0107 \\
\hline $15-3-2019$ & 0.0037 & 0.0256 & 0.0022 & 0.0204 & 0.0152 \\
\hline 22-3-2019 & 0.0179 & 0.0143 & 0.0214 & -0.0116 & 0.0158 \\
\hline 29-3-2019 & -0.0020 & -0.0059 & 0.0017 & -0.0030 & 0.0183 \\
\hline $5-4-2019$ & -0.0031 & 0.0038 & 0.0193 & 0.0167 & 0.2062 \\
\hline $12-4-2019$ & 0.0079 & 0.0259 & 0.0079 & 0.0066 & 0.0104 \\
\hline 19-4-2019 & 0.0067 & -0.0030 & 0.0101 & -0.0006 & 0.0412 \\
\hline $26-4-2019$ & 0.0007 & 0.0059 & 0.0077 & 0.0029 & -0.0046 \\
\hline $3-5-2019$ & 0.0129 & -0.0304 & 0.0033 & -0.0227 & 0.0886 \\
\hline $10-5-2019$ & -0.0015 & -0.0171 & -0.0166 & -0.0564 & 0.1006 \\
\hline $17-5-2019$ & 0.0128 & -0.0294 & -0.0098 & -0.0035 & 0.1409 \\
\hline $24-5-2019$ & 0.0064 & 0.0036 & -0.0042 & 0.0018 & 0.0840 \\
\hline $31-5-2019$ & -0.0136 & 0.0218 & 0.0364 & 0.0231 & 0.0709 \\
\hline $7-6-2019$ & 0.0126 & 0.0062 & 0.0097 & 0.0183 & -0.0639 \\
\hline
\end{tabular}

Source: Authors' calculations (R-Studio), Thomson Reuters and CoinMarketCap.

On a weekly based returns, indices performance, efficient frontier, weights and comparison of distributions can be shown graphically. Furthermore, performance of portfolio components will be shown (Figure 1). 


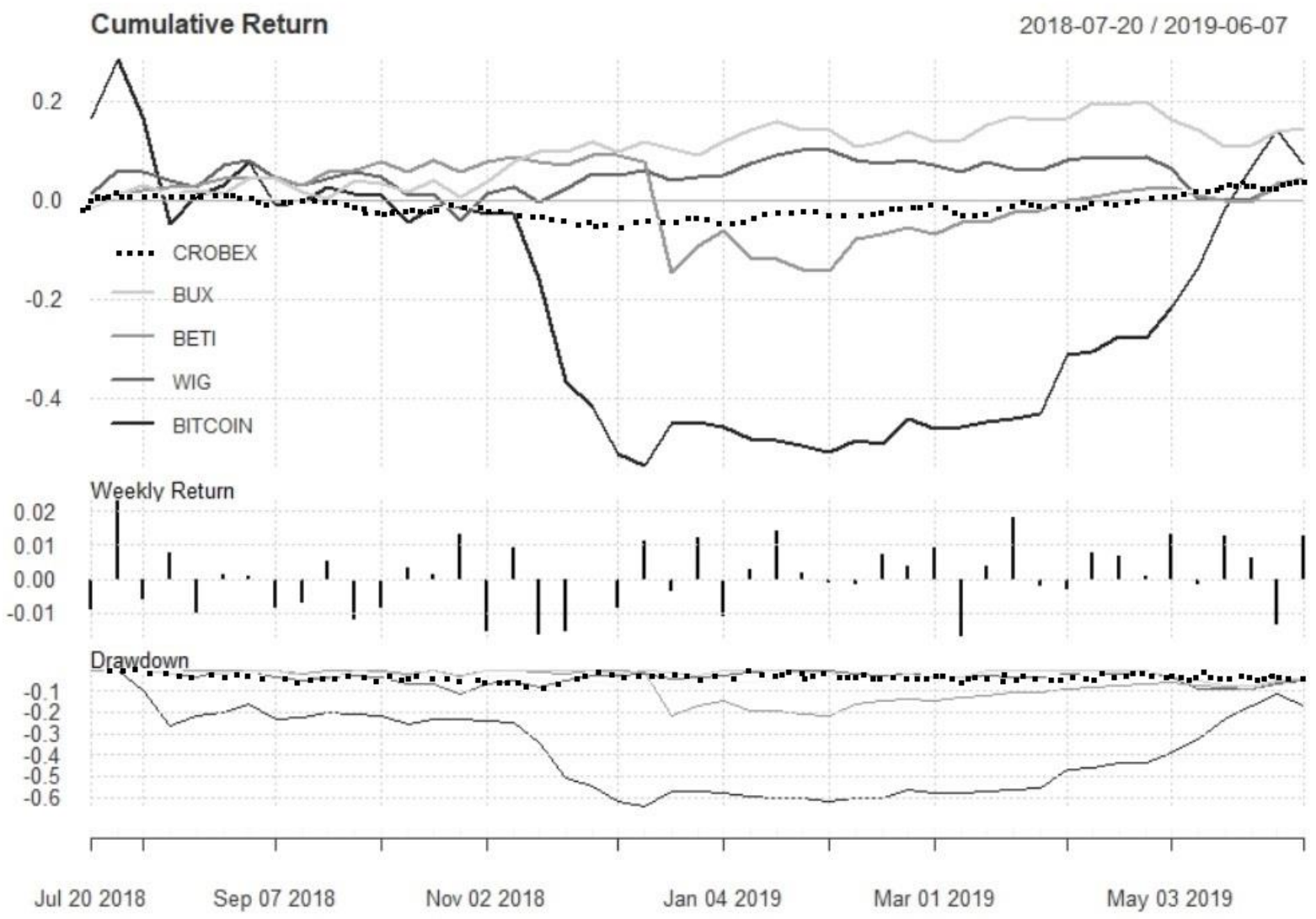

Figurel Performance graph of selected emerging market indices and one cryptocurrency

Source: Authors' creation (R-Studio), Thomson Reuters and CoinMarketCap.

From the MPT point of view, the riskiest component in portfolio is Bitcoin because of the highest prices volatility. Bitcoin riskiness is followed by Polish (WIG) and Romanian (BETI).

When it comes to performance, in figure 2. comparison of distributions is illustrated by creating a histogram of returns generated for portfolio components with different display options.

A rational investor should prefer a positively skewed asset to a similar negative skewed asset and asset with a low to negative kurtosis in order to indicate more predictable returns (Carl and Peterson, 2019). 

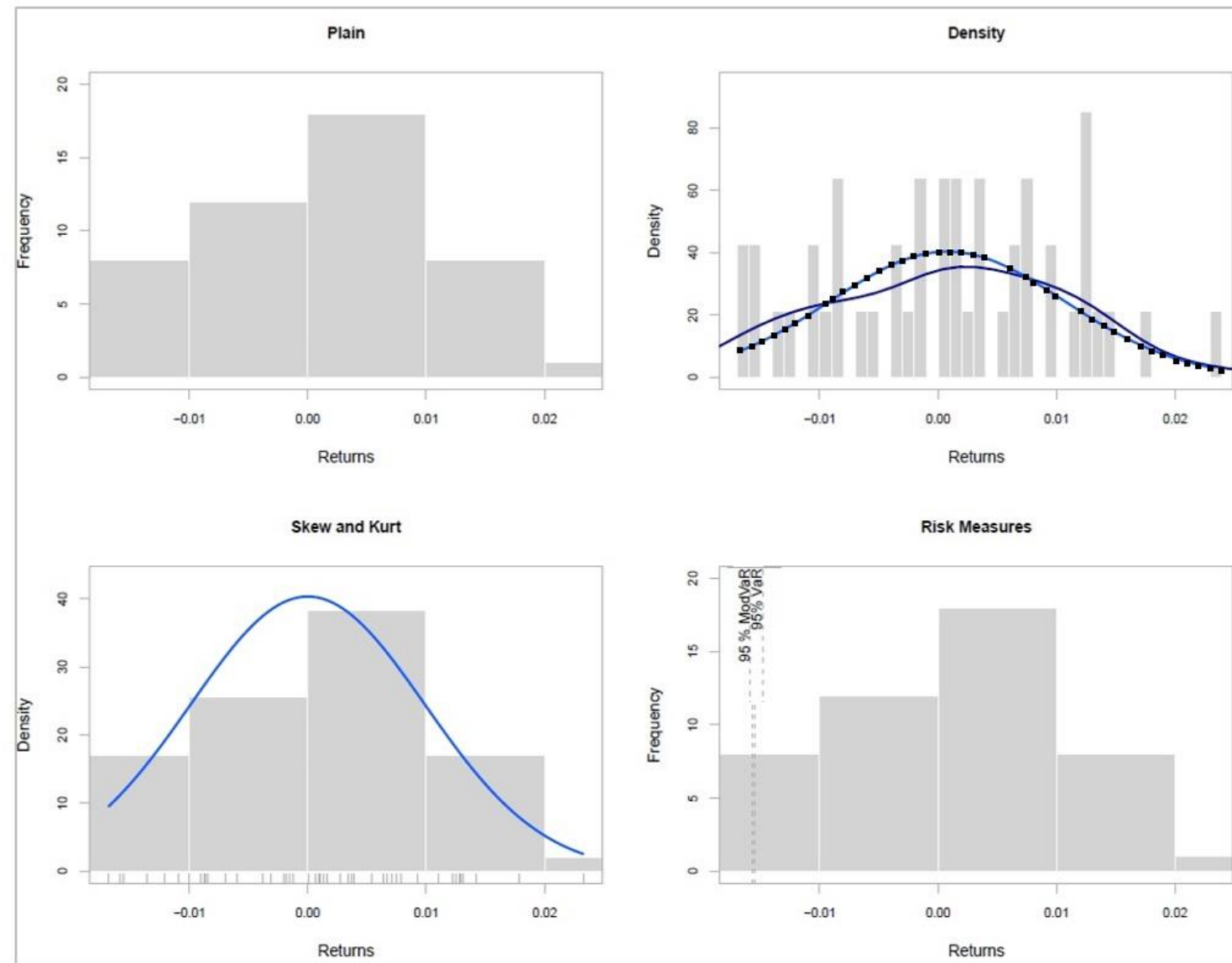

Figure 2 Comparison of distributions of portfolio components Source: Authors' creation (R-Studio), Thomson Reuters and CoinMarketCap.

Table 2 Variance-covariance matrix

\begin{tabular}{|l|l|l|l|l|l|}
\hline & CROBEX & BUX & BETI & WIG & BITCOIN \\
\hline CROBEX & $\mathbf{9 . 7 9 E - 0 5}$ & $-2.73 E-05$ & $1.02 E-05$ & $6.70 \mathrm{E}-06$ & 0.000175 \\
\hline BUX & $-2.73 \mathrm{E}-05$ & $\mathbf{0 . 0 0 0 3 8 2}$ & 0.000114 & 0.000243 & -0.00021 \\
\hline BETI & $1.02 \mathrm{E}-05$ & 0.000114 & $\mathbf{0 . 0 0 1 4 2 6}$ & 0.000186 & -0.0005 \\
\hline WIG & $6.70 \mathrm{E}-06$ & 0.000243 & 0.000186 & $\mathbf{0 . 0 0 0 5 1 7}$ & $3.67 \mathrm{E}-05$ \\
\hline BITCOIN & 0.000175 & -0.00021 & -0.0005 & $3.67 \mathrm{E}-05$ & $\mathbf{0 . 0 0 7 9 2 4}$ \\
\hline
\end{tabular}

Source: Authors' calculations (R Studio), Thomson Reuters and CoinMarketCap.

On the diagonal of variance-covariance matrix there are variances that show the riskiness of a certain component of the portfolio. It can be observed that the riskiest component of the portfolio is BITCOIN with the $0.79 \%$ weekly variance.

Table 3 Correlation matrix

\begin{tabular}{|l|c|c|c|c|c|}
\hline & CROBEX & BUX & BETI & WIG & BITCOIN \\
\hline CROBEX & 1.0000 & -0.1409 & 0.0271 & 0.0297 & 0.1991 \\
\hline BUX & -0.1409 & 1.0000 & 0.1539 & 0.5467 & -0.1194 \\
\hline BETI & 0.0271 & 0.1539 & 1.0000 & 0.2160 & -0.1502 \\
\hline WIG & 0.0297 & 0.5467 & 0.2160 & 1.0000 & 0.0181 \\
\hline BITCOIN & 0.1991 & -0.1194 & -0.1502 & 0.0181 & 1.0000 \\
\hline
\end{tabular}

Source: Authors' calculations (R Studio), Thomson Reuters and CoinMarketCap.

From table 3 , it can be noticed that BITCOIN has negative correlation with BUX and BETI. Negative correlation means that if BITCOIN prices increase, prices of other 
portfolio components will decrease. Furthermore, strength of the linear relationship between BITCOIN and other portfolio components are extremely weak. It is noticeable that the highest correlation is between WIG and BUX. Strength of the linear relationship between these two components can be interpreted as moderate. In addition to variance and correlation matrix, an efficient frontier will be illustrated in figure 3.

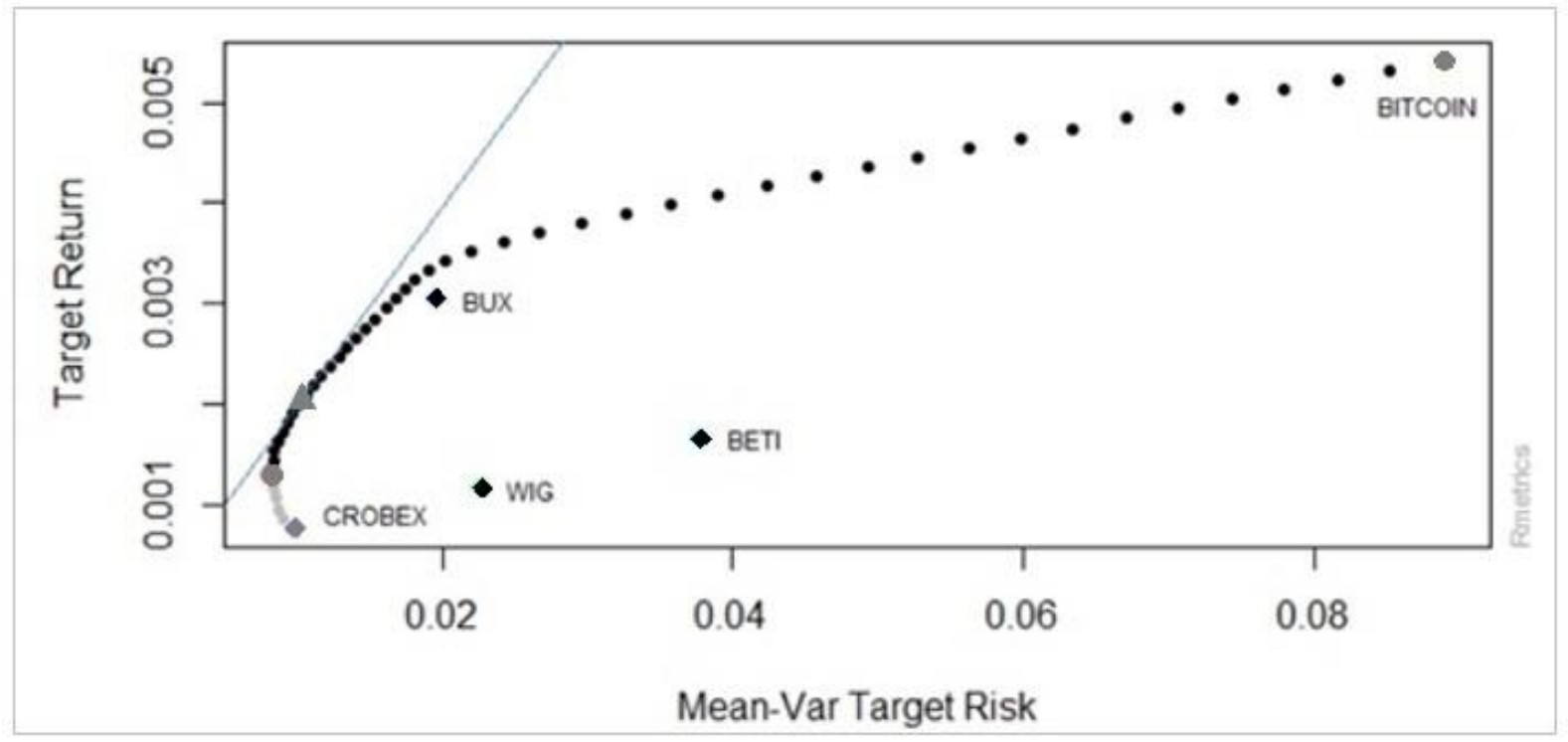

Figure 3 Efficient frontier

Source: Authors' creation (R-Studio), Thomson Reuters and CoinMarketCap.

In figure 3, the position of the components of the portfolio relative to the efficient frontier is shown. A red dot indicates a minimum variance portfolio. Moreover, a red dot achieves a certain level of return with a given level of risk. If there was an increase in risk, the level of return would also increase. The blue point through which the tangent passes indicates the so-called tangency portfolio. Tangency portfolio is the portfolio with the highest Sharpe ratio. Nevertheless, that is the most efficient portfolio from risk and reward standpoint. The y-axis from which the direction originates is the point at which the variance is zero. It is important to emphasize that, for this reason, expected returns and standard deviations are in a linear relationship. This would mean that if the expected return increase, the standard deviation would also increase by the same percentage point. The tangent contains efficient portfolios consisting of risky components. Therefore, it can be concluded that the portfolio at the intersection point is composed of risky components. Additionally, tangency portfolio has a higher risk than minimum-variance portfolio, but with a higher risk, the portfolio also obtains higher returns since the relationship between risk and the return on the tangent is linear.

It can be concluded that tangency portfolio offers the best combination of risk and return since it has the highest Sharpe ratio. In addition to efficient frontier and tangency portfolio, in figure 4 annualized Sharpe ratios for each point on the efficient frontier are shown. Furthermore, in figure 5 the frontier weights are shown, figure 6 shows minimum-variance and figure 7 shows tangency weights. 


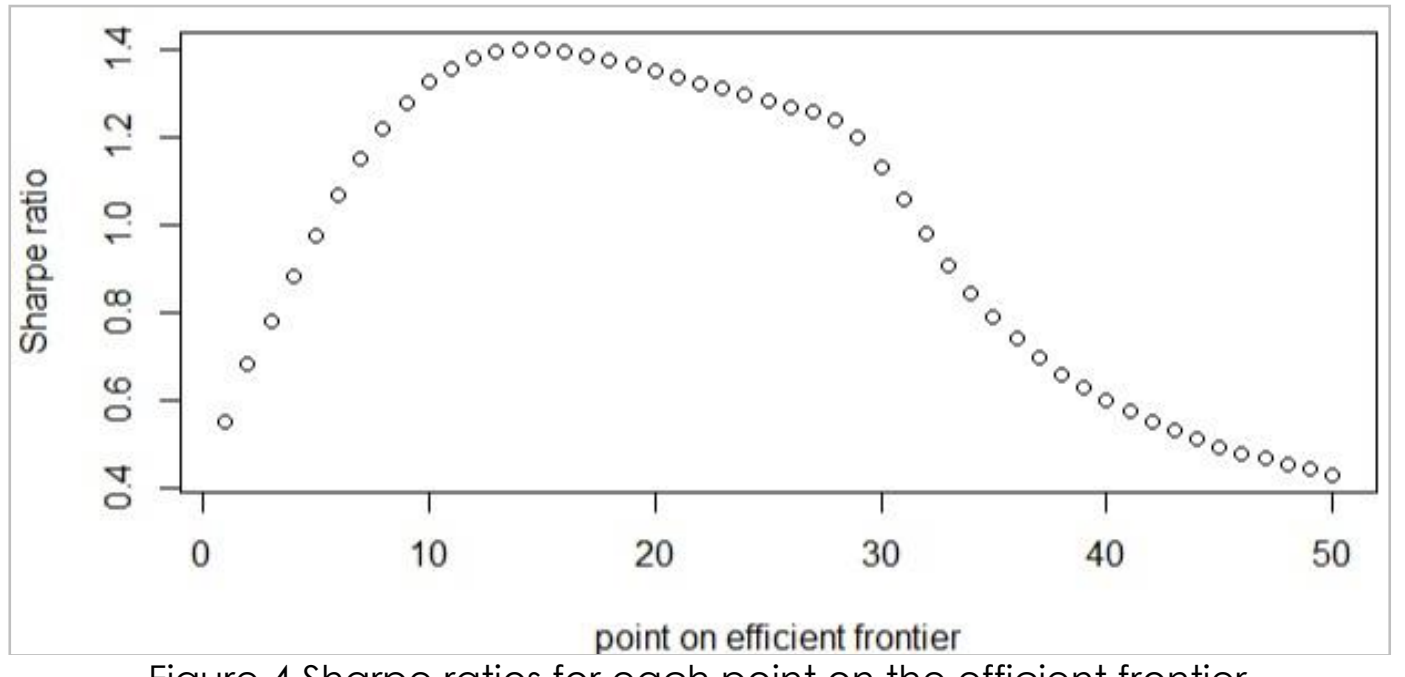

Figure 4 Sharpe ratios for each point on the efficient frontier Source: Authors' creation (R-Studio), Thomson Reuters and CoinMarketCap.
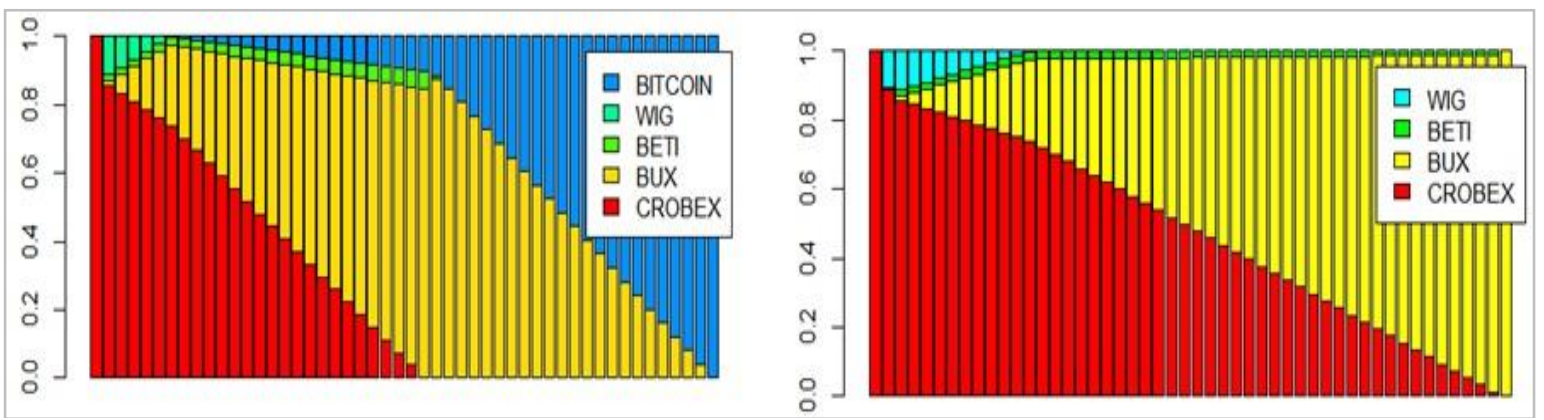

Figure 5 Frontier weights for both portfolios

Source: Authors' creation (R-Studio), Thomson Reuters and CoinMarketCap.

In figure 5, weights on the efficient frontier with and without BITCOIN are illustrated in order to compare the small differences in all iterations of the weights. It is important to stress that these are not optimal weights.

In figure 6, minimum-variance portfolio weights are shown. Furthermore, pie chart does not show BITCOIN, since BITCOIN is the riskiest asset in the portfolio and from the MPT perspective, investors have high risk aversion and they don't want to invest in very risky assets. In order to calculate Mean-variance portfolio weights, solveRquardprog was used. Pie chart also shows that investor should invest most of his assets in CROBEX (74.89\%) followed by BUX (21.65\%). The reason for this is that CROBEX has the smallest risk and it is located on the bottom of an efficient frontier at shown in figure 3.

In figure 7 , tangency portfolio weights were illustrated. It is noticeable that BITCOIN allocation is $3.96 \%$. In other words, if its known that tangency portfolio is the most efficient portfolio with the highest Sharpe ratio it can be concluded that investors will include BITCOIN if they want to achieve certain level of efficiency. Furthermore, investor will allocate most of his assets in CROBEX (46.47\%) followed by BUX (46.13\%). These two indices have almost even allocation in tangency portfolio in comparison to minimum-variance portfolio. Furthermore, WIG allocation is $0.00 \%$ that's why it is not included in figure 7. In addition to optimal weights, in figure 8, two efficient frontiers will be compared. One efficient frontier will include BITCOIN and the other wont. 


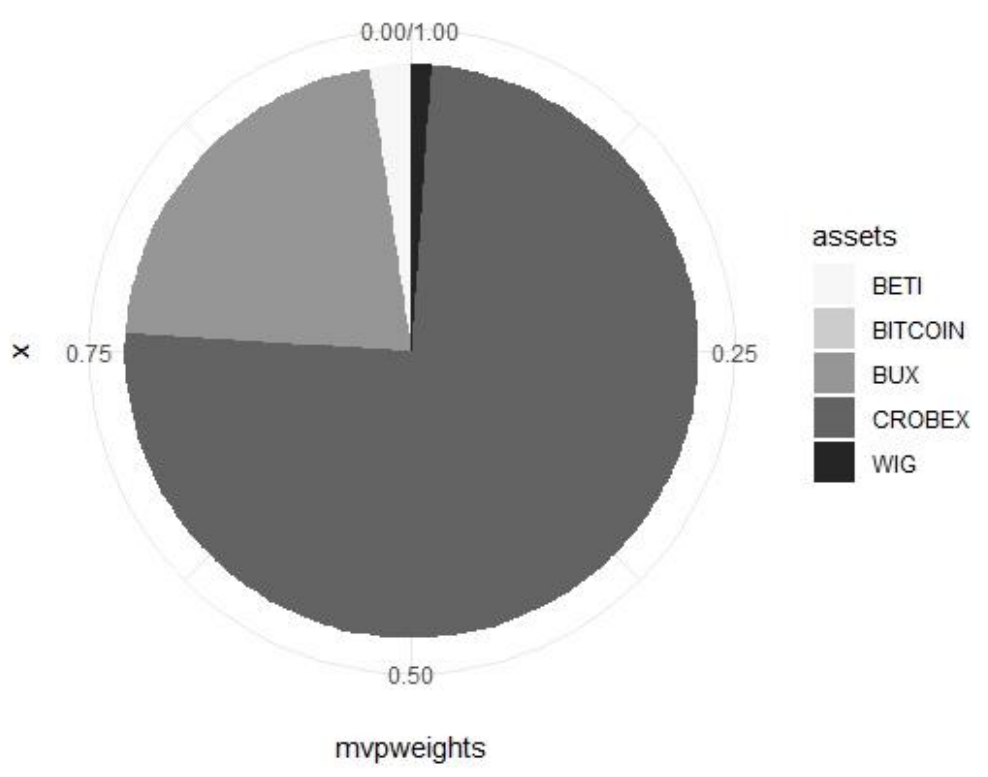

Figure 6 Minimum-variance portfolio weights

Source: Authors' creation (R-Studio), Thomson Reuters and CoinMarketCap.

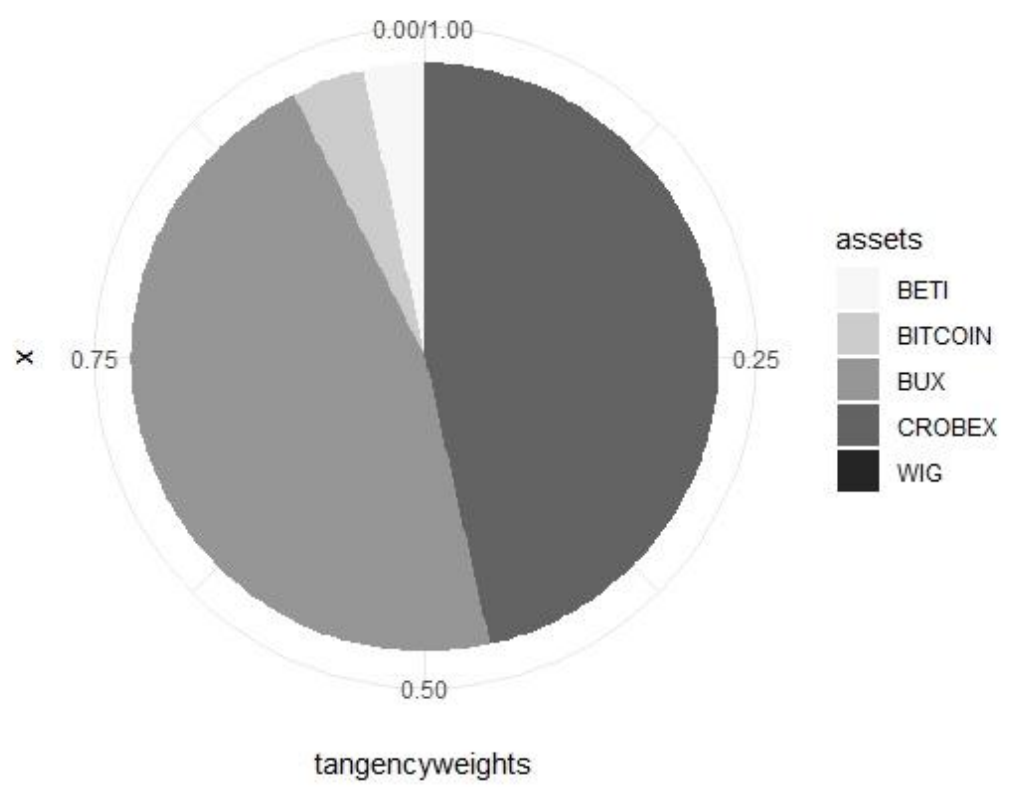

Figure 7 Tangency portfolio weights

Source: Authors' creation (R-Studio), Thomson Reuters and CoinMarketCap. 


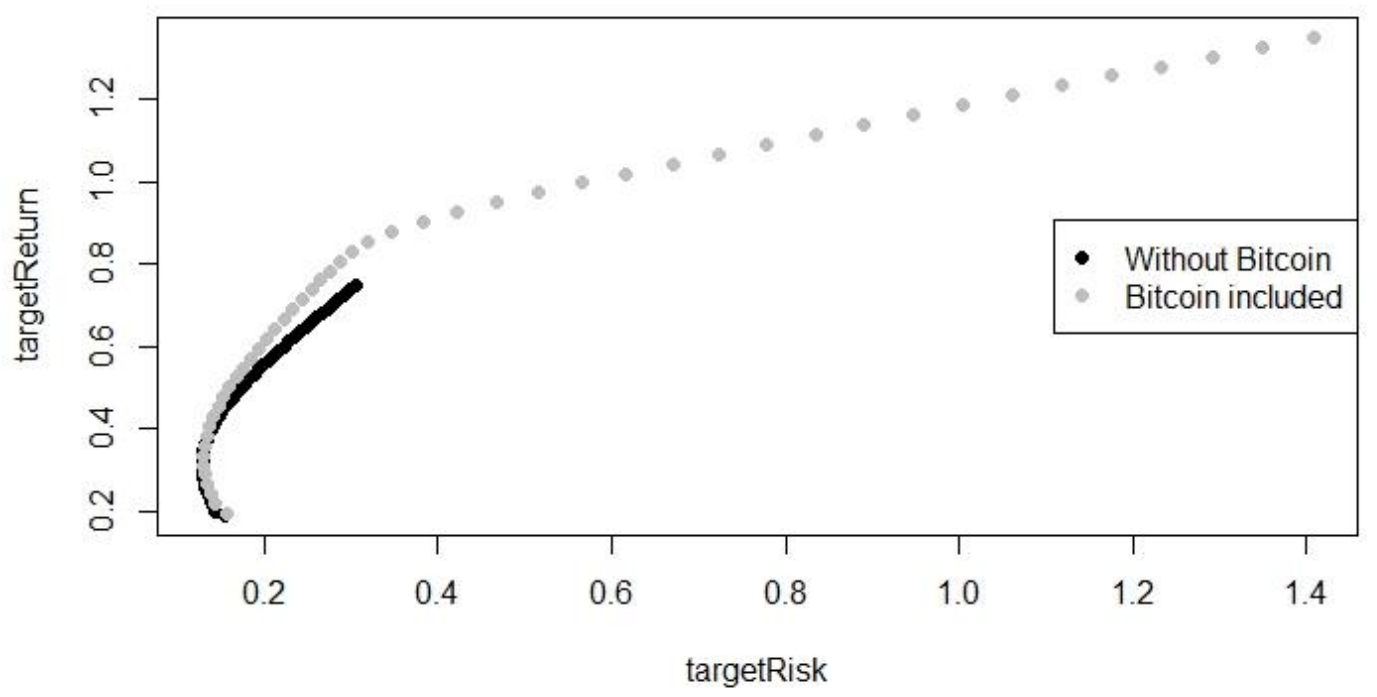

Figure 8 Comparison of efficient frontiers

Source: Authors' creation (R-Studio), Thomson Reuters and CoinMarketCap.

Figure 8 shows two efficient frontiers. A red efficient frontier represents an efficient frontier that includes BITCOIN. A blue efficient frontier does not include the specified cryptocurrency. It can be seen that an efficient frontier with Bitcoin included is above an efficient frontier without BITCOIN included. For example, it can be observed that at $0.18 \%$ risk level, a non-BITCOIN portfolio has a return of $0.15 \%$ at the $0.18 \%$ risk level, a portfolio with Bitcoin earns a greater return of $0.18 \%$ with the same amount of risk. Returns are higher than that without BITCOIN, and the reason is higher volatility in BITCOIN prices. Given that for the same level of risk, in some cases, even a lower level of risk, a portfolio with BITCOIN gives a higher returns, it can be concluded that the inclusion of cryptocurrency in the portfolio increases its efficiency.

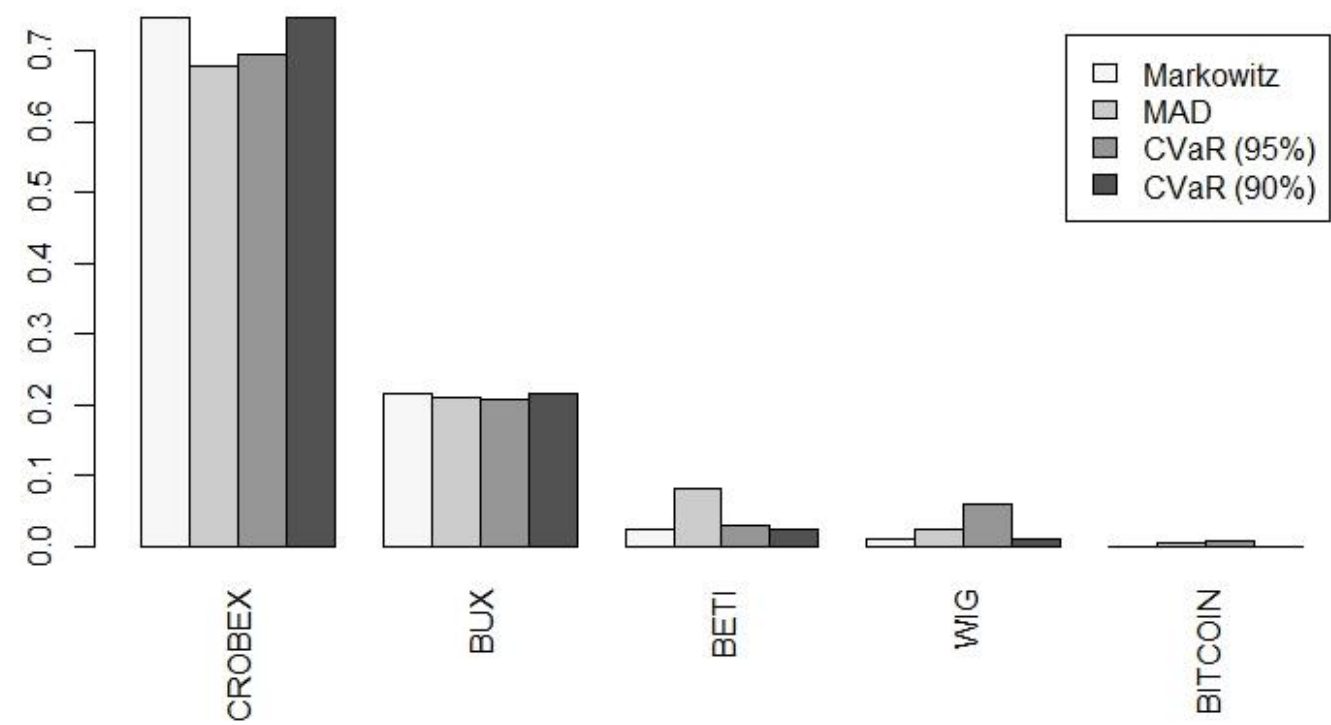

Figure 9 Comparison of contemporary risk measures Source: Authors' creation (R-Studio), Thomson Reuters and CoinMarketCap. 
In addition to Markowitz risk measure a comparison of standard deviation and contemporary risk measures is illustrated in figure 9. In figure 9, it can be noticed that different risk measures provide slightly different solutions. It can also be seen that Markowitz risk measure and Conditional Value at Risk (90\%) that measure the level of financial risk in portfolio are the same in almost every portfolio component.

\section{Conclusion}

After conducting the empirical analysis, it can be concluded that the introduction of BITCOIN cryptocurrency into the portfolio really leads to an increase in portfolio efficiency. This can be noticed in returns that are even higher at lower risk than the non-BITCOIN portfolio.

Another fact that demonstrates greater portfolio efficiency with BITCOIN is the position on the efficient frontier, which is largely above the efficient frontier of a portfolio without BITCOIN. This confirms second hypothesis about shape of an efficient frontier. It is important to emphasize that the efficient frontiers overlap in the lower part after which they slowly diverge. The reason is that Markowitz modern portfolio theory does not include transaction costs and taxes, so the maximum expected return with a given level of risk is the same in both portfolios. In other words, since this theory does not include transaction costs and taxes, the inclusion of BITCOIN does not show as much advantage as it should.

Considering another theory, it is assumed that BITCOIN would increase portfolio efficiency even more. Notwithstanding the shortcomings of Markowitz theory, it can be seen that a portfolio with BITCOIN included also brings significantly higher returns compared to non-BITCOIN portfolio.

The second conclusion is based on the position of the components of the portfolio and the position of BITCOIN on the efficient frontier of the selected countries. Figure 3. shows that BITCOIN is above the other components of the portfolio, which means that it has the highest risk but also carries the highest returns. It is also important to note that only CROBEX and BITCOIN are on the efficient frontier, while the rest of the portfolio components are below the efficient frontier. The reason is that CROBEX has the lowest risk in the portfolio and BITCOIN has the highest return. Likewise, the components that lie on the efficient frontier can be characterized as efficient components, so all components to the right of the efficient frontier are inferior from the risk and reward point of view, than the components at the efficient frontier. Considering that BITCOIN is on the efficient frontier, above all other components, it can be concluded that from this perspective, it increases the efficiency of the entire portfolio because it provides higher returns with lower level of risk when it is included into the portfolio.

\section{References}

1. Aljinović, Z., Marasović, B., Šego, B. (2011). Financijsko modeliranje. Split: Sveučilište u Splitu, Ekonomski fakultet Split.

2. Andrianto, Y, Diputra, Y. (2018). The effect of Cryptocurrency on investment portfolio effectnivess. Journal of finance and accounting, Vol. 6, No. 5, pp. 229-238.

3. Berentsen, A., Schar, F. (2018). A short introduction of the world of cryptocurrencies. Federal Reserve Bank of ST. Lois Review, Vol. 100, No. 1, pp. 5-7.

4. Burniske, C., White, A. (2016). Bitcoin: Ringing the Bell for a New Asset Class. ARK Invest \& Coinbase, pp. 1-24.

5. Dumičić, K., Bahovec, V. (eds.) (2018). Poslovna statistika. Zagreb: Element.

6. Fabozzi, J. F., Gupta, F., Markowitz, H. M. (2002). The Legacy of Modern Portfolio Theory, The Journal of Investing Fall, Vol. 11, No. 3, pp. 7-22. 
7. Fung, B., Halaburda, H. (2014). Understanding Platform-Based Digital Currencies, Bank of Canada Review. pp. 12-20. Available at https://www.bankofcanada.ca/wpcontent/uploads/2014/05/boc-review-spring 14-fung.pdf [09 October 2019].

8. Hileman, G., Rauchs, M. (2017). Global cryptocurrency banchmarking study. Cambridge: University of Cambridge, pp. 1-110.

9. Houben, R., Snyers, A. (2018). Cryptocurrencies and blockchain, Legal context and implications for financial crime, money laundering and tax evasion. Policy Department for Economic, Scientific and Quality of Life Policies. European Parliament. Available at http://www.europarl.europa.eu/cmsdata/150761/TAX3\%20Study\%20on\%20cryptocurrenci es\%20and\%20blockchain.pdf [01 October 2019].

10.Jakšić, S. (2007). Primjena Markowitzeve teorije na tržište dionica Zagrebačke burze, Zbornik Ekonomskog fakulteta u Zagrebu, Vol. 5, No. 1, pp. 331-344.

11.Jerončić, M., Aljinović, Z. (2011). Formiranje optimalnog portfelja pomoću Markowitzevog modela uz sektorsku podjelu kompanija. Ekonomski pregled. Vol. 62, No. 9-10, pp. 583-606.

12.Lischewski, J., Voronkova, S. (2012). Size, value and liquidity. Do They Really Matter on an Emerging Stock Market?, Emerging Markets Review. Vol. 13, No. 1, pp. 8-25.

13.Mangram, E. M. (2013). A simplified perspective of the Markowitz Portfolio theory, Global Journal of Business Research, Vol. 7, No. 1, pp. 59-70.

14.Markowitz, H. M. (1959). Portfolio Selection: Efficient Diversification of Investments. John Wiley \& Sons, New York.

15. Michaud, R., Michaud, R. (2007). Estimation Error and Portfolio Optimization A Resampling Solution, New Frontier Advisors. LLC, Boston, pp. 1-24.

16.Osterrieder, J., Chan, S., Chu, J., Nadarajah, S. (2017). A Statistical Analysis of Cryptocurrencies. Manchester: University of Manchester, pp. 1-30.

17.Peris, D. (2018). Getting Back to Business. New York: McGraw-Hill Education.

18.Škrinjarić, T. (2013). Mjerenje diverzifikacije portfelja. Zbornik Ekonomskog fakulteta u Zagrebu, Vol. 11, No. 1, pp. 67-79.

19.Trimborn, S., Li, M., Härdle, W. K. (2017). Investing with cryptocurrencies- A liquidity constrained investment approach, SFB 649 Discussion Paper 2017-014. Humboldt University Berlin, pp. 1-37. Available at http://sfb649.wiwi.hu-berlin.de/papers/pdf/SFB649DP2017014.pdf [ 09 October 2019].

20.Tomić Plazibat, N., Aljinović, Z., Marasović, B. (2006). Matematički modeli u financijskom upravljanju. Split: Sveučilište u Splitu, Ekonomski fakultet Split.

21.Carl, P., Brian, G. P. (2019). PerformanceAnalytics Charts and Tables Overview. Available at https://cran.r-project.org/web/packages/PerformanceAnalytics/vignettes/PA-charts.pdf [10 October 2019].

22. CoinMarketCap (2019). Available at https://coinmarketcap.com/ [14 October 2019].

\section{About the authors}

Karlo Ćosić graduated in 2019 at University of Zagreb Faculty of Economics and Business, majoring in Analysis and Business Planning. He received master's degree with the master's thesis "The impact of cryptocurrency on efficient frontier of emerging markets". The author can be contacted at karlo.cosic7@gmail.com.

Anita Čeh Časni, PhD is Assistant Professor at University of Zagreb Faculty of Economics and Business (FEB), Department of Statistics. She received PhD in Quantitative Economics at FEB with the dissertation thesis "Modelling housing wealth effect on consumption". She was also educated at the GSE - Summer School in Barcelona in Panel data analysis. Her main research interests are applied statistical analysis in macroeconomics, finance and tourism. She is actively engaged in number of scientific projects. The author can be contacted at aceh@efzg.hr. 